\title{
Aortic Dissection In Case with Chronic Kidney Disease
}

\author{
Banu BÜYÜKAYDIN ${ }^{1}$, Murat ALAY², Rumeyza KAZANCIOĞLU³ ${ }^{3}$ Aycan UĞUR ${ }^{4}$, Muhammed TUNÇ \\ Melike Elif TEKER ${ }^{5}$, Bekir INAN ${ }^{6}$, Reha ERKOÇ \\ ${ }^{1}$ Department of Internal Medicine, Bezmialem Vakıf University School of Medicine, İstanbul, Turkey \\ ${ }^{2}$ Department of Endocrinology, Yüzüncü Yil University School of Medicine, Van, Turkey \\ ${ }^{3}$ Department of Nephrology, Bezmialem Vakıf University School of Medicine, İstanbul, Turkey \\ ${ }^{4}$ Department of Internal Medicine, Clinic of Meditime Surgery Medicine, İstanbul, Turkey \\ ${ }^{5}$ Department of Cardiovascular Surgery, Medical Park Hospital, İstanbul, Turkey \\ ${ }^{6}$ Department of Cardiovscular Surgery, Bezmialem Vakıf University, İstanbul, Turkey
}

\section{ABSTRACT}

Aortic disection is an urgent clinical problem that rapid diagnosis and appropriate treatment is life-saving. Hypertension is one of the major risk factors. In this paper, a 56 years old female patient with hypertension and renal failure was presented. In this case after clinical suspicion, aortic dissection was diagnosed with imaging studies. Endovascular aortic repair was performed but after surgery, patient died because of possible hemorrhage complication. In aortic disection, diagnosis and treatment could be fast. In chronic kidney disease the prognosis of patients is adversely affected. Despite proper surgical intervention accompanying medical problems like chronic kidney disease have negative effects on survival.

Keywords: Aortic disection, hypertension, chronic kidney disease

\section{Introduction}

Aortic dissection is the presence of blood between the layers of the aortic wall. Multiple risk factors are responsible for this condition. Among these factors, hypertension is the most important one because of its incidence (1). This study presents the case of a patient with aortic dissection (AD) with hypertension and renal failure.

\section{Case Presentation}

A 56-year-old female patient was admitted with complaints of nausea, vomiting, shortness of breath, swelling on the feet, and back pain. She had hypertension known for 5 years, and her complaints had begun 15 days ago. In the physical examination, her blood pressure was $160 / 90 \mathrm{mmHg}$ and no difference was observed between the extremities. No pathology was found in other system examinations. The initial laboratory values of the patient are given in Table 1.

The patient was hospitalized because of the diagnoses of hypertension and acute renal failure. During follow-up, severe pain developed in her back and abdomen. In the computed tomography (CT) and CT angiography, aortic dissection extending from the thoracic level in the descending aorta to the iliac artery was observed (Figure 1). The patient, who did not have diuresis in the follow-up, underwent hemodialysis. For dissection, endovascular aortic repair (EVAR) was performed by the department of cardiovascular surgery and the patient was followed up (Figure 2, 3).

The echocardiography did not reveal any valve anomaly, whereas renal scintigraphy demonstrated findings consistent with chronic renal failure and chronic hemodialysis program was planned. While the general condition of the patient was stable, sudden deterioration occurred in the hemodynamics. She died due to abundant bleeding under medical support.

Cite this article as: Büyükaydın B, Alay M, Kazancıoğlu R, Uğur A, Tunç M, Teker EM. Aortic Dissection In Case with Chronic Kidney Disease. Bezmialem Science 2017; 5: 186-8. 
Table 1. Laboratory data of patient

\begin{tabular}{l|c|c} 
& Observed value & Normal value \\
\hline Glucose (mg/dL) & 247 & $70-110$ \\
Sodium (mmol/L) & 130 & $135-145$ \\
Potassium (mmol/L) & 5.0 & $3.5-5.5$ \\
BUN (mg/dL) & 107 & $5-23$ \\
Creatinine (mg/dL) & 12.4 & $0.6-1.2$ \\
ALT (U/L) & 25 & $0-55$ \\
AST (U/L) & 49 & $5-35$ \\
LDH (U/L) & 2049 & $210-425$ \\
Leukocyte & 18000 & $4-10000 / \mathrm{mm}^{3}$ \\
HCT & $22.7 \%$ & $35 \%-45 \%$ \\
Hb (g/dL) & 7.8 & $11.5-15$ \\
Platelet & 71000 & $150-400000 / m^{3}$ \\
CK (U/L) & 168 & $30-135$ \\
\hline BUN: blood urea nitrogen, ALT: alanine aminotransferase, AST: \\
aspartate aminotransferase, LDH: lactate dehydrogenase, HCT: \\
hematocrit, Hb: hemoglobin, CK: creatine kinase
\end{tabular}

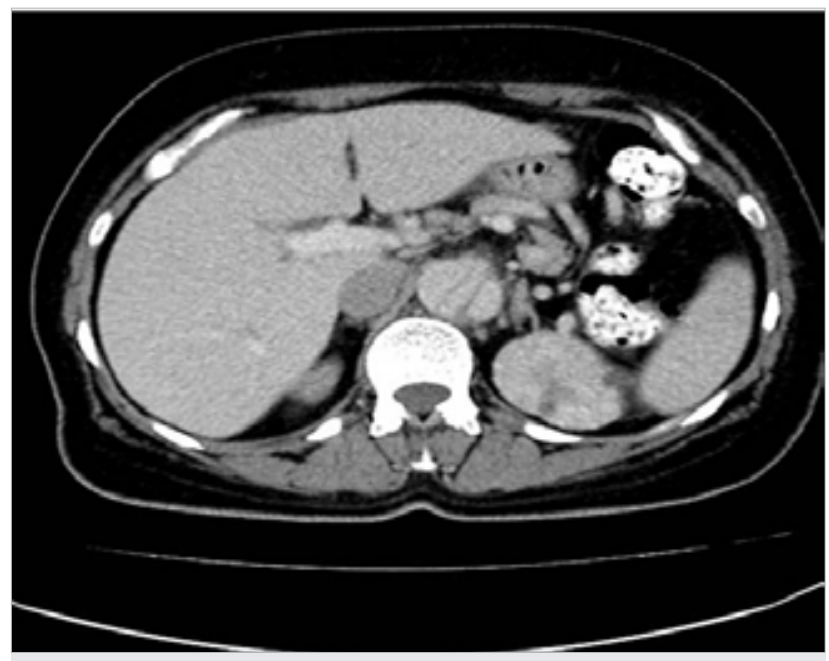

Figure 1. View of aortic dissection before the procedure through helical computed tomography

\section{Discussion}

Aortic dissection is the separation of the tunica media due to rupture in the aortic intima and the filling of the aortic wall with blood. It is more frequent in men between the $4^{\text {th }}$ and $7^{\text {th }}$ decades. The risk factors include hypertension, congenital heart diseases, advanced atherosclerosis, vasculitis, trauma, pregnancy, familial history, and genetic reasons. Hypertension, which was seen in our patient, is the most common factor. Moreover, age and renal failure are also additional risk factors. Destruction in the aortic media, a decrease in the elastin and collagen fibrolamellar unit, intimal tear, and rupture develop (2).

Dissection is evaluated with the DeBakey and Stanford classification systems $(3,4)$. According to the DeBakey system,

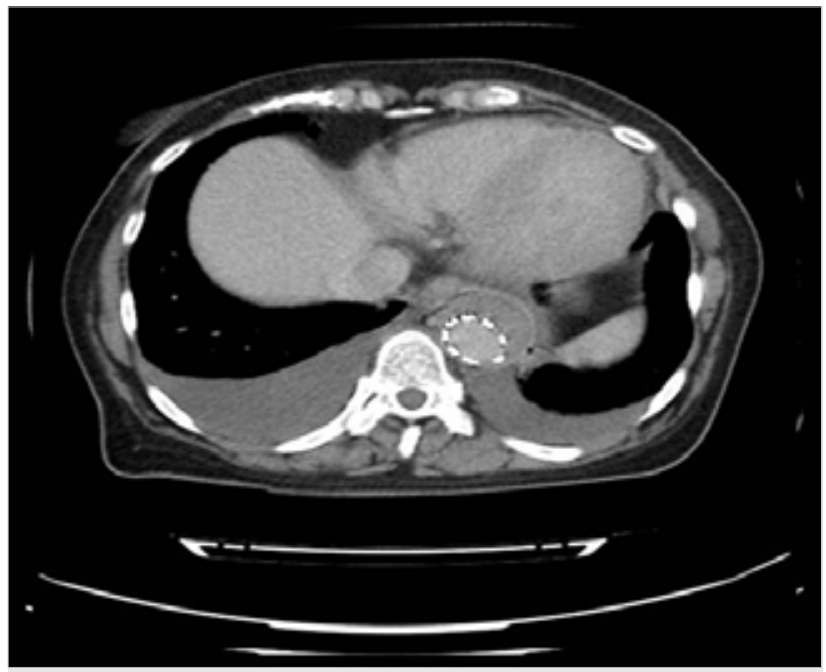

Figure 2. Horizontal imaging after endovascular aortic repair procedure

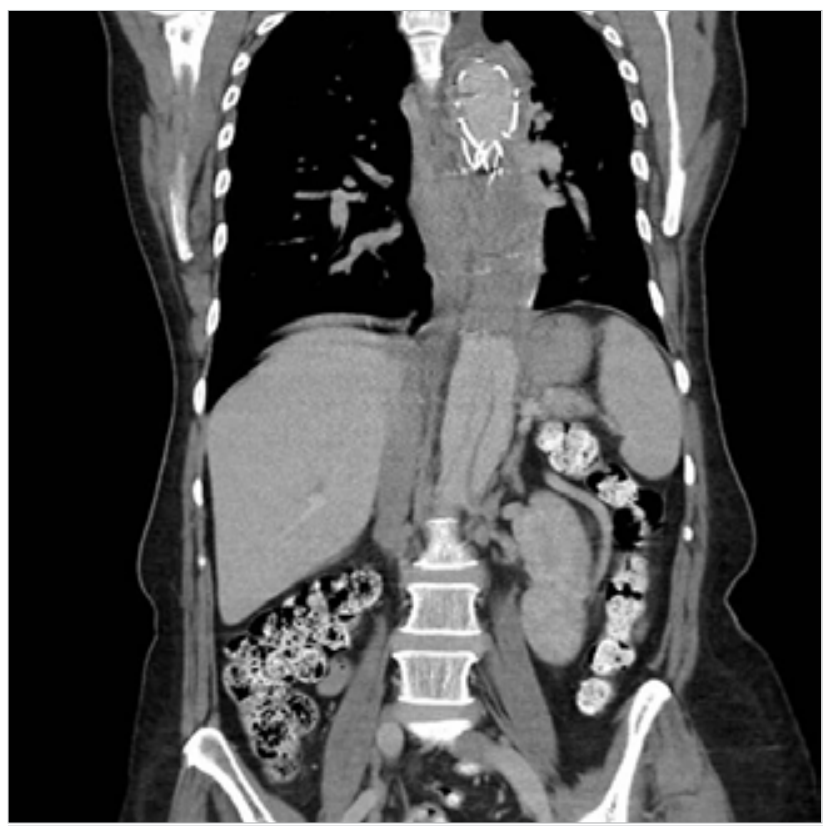

Figure 3. Sagittal imaging after endovascular aortic repair procedure

type I originates in the proximal aorta and involves the whole aorta, type II involves only the ascending aorta, and type III involves only the descending aorta. In the Stanford classification system, type $\mathrm{A}$ is limited to the ascending aorta and type $\mathrm{B}$ involves the descending aorta. Our patient had type III and type B AD.

The most frequently encountered clinical symptom is the sudden onset of severe pain in the chest, back, or lower back. In physical examinations, hyper or hypotension, tachycardia, newly developed murmur of aortic insufficiency, tamponade findings, pulse deficit, and syncope can be detected and this condition can rarely present without pain. Our patient had severe pain in her back and abdomen. No abnormality was detected, except minimally increased blood pressure. 
Aortography, helical CT, CT angiography, and transesophageal echocardiography are used for the diagnosis of $\mathrm{AD}$ (5). However, helical CT is more preferred currently (5). In our case, the diagnosis of our patient was confirmed through this technique. The treatment of $\mathrm{AD}$ is surgical intervention and it can be required once the diagnosis is established. Currently, the preferred technique is the EVAR procedure, which has a lower risk for the development of complications compared with open surgery. The protection of renal perfusion is very important in these patients. Decreased dose of contrast agent and monitorization of renal function positively affect renal and cardiac insufficiency (6). In a meta-analysis including 42 nonrandomized studies, the rates of early mortality, paraplegia, renal failure, need for transfusion, postoperative bleeding, cardiac complications, pneumonia, and hospitalization were reported to be lower in this technique than in open surgery (7). As in our case, leakage and defects associated with the process have an important place among the causes of mortality after EVAR.

Informed consent for this case report could not be received from the patient because her general condition suddenly deteriorated while she was stable and emergency intervention was required.

\section{Conclusion}

Aortic dissection is a clinical condition that has a high mortality and requires early treatment. The important risk factors include hypertension and renal failure. With appropriate surgical intervention, a decrease in the morbidity and mortality rates can be observed.

Peer-review: Externally peer-reviewed.
Author Contributions: Concept - R.K., R.E.; Design - B.İ.; Supervision - R.K.; Resources - R.E., B.İ., M.E.T.; Data Collection and/or Processing - M.A., B.B., A.U., M.T.; Analysis and/or Interpretation - M.E.T., B.İ., R.E.; Literature Search - B.B., A.U., M.T., M.A.; Writing Manuscript - B.B., M.T., M.A.; Critical Review - R.K., R.E., M.E.T., M.A.

Conflict of Interest: No conflict of interest was declared by the authors.

Financial Disclosure: The authors declared that this study has received no financial support.

\section{References}

1. Franco KL, Verrier ED. Advanced Therapy in Cardiac Surgery Eds. BC Decker Inc.; 1999 (32): p 296-310.

2. Michael A. Coady, MD, MPH, John A. Rizzo, PhD, Lee J. Goldstein, BA John A. Elefteriades, MD Natural history, pahogenesis and etiyology of thorasic aortic aneurysms and dissecitons. Cardiol Clin 1999; 17: 615-35. [CrossRef]

3. ME DeBakey, WS Henley, DA Cooley, GC Morris, ES Crawford, AC Beall. Surgical management of dissecting aneurysms of the aorta. J Thorac Cardiovasc Surg 49; 130-149.

4. Nakashima Y, Kurzumi T, Sueshşi K, et al. Dissecting aneursym: a clinicopathologic and histopathologic syudy of 111 autopsied cases. Hum Pathol 1990; 21: 291-296. [CrossRef]

5. Tongfu Yu, MD, Xiaomei Zhu, MD, Lijun Tang, MD, Dehang Wang, MD. Nael Saad MB. Review of CT Angiography of Aorta. Radiol Clin North Am 2007; 45: 461-483. [CrossRef]

6. Handa N, Tomita S, Kato M, Nishio I, Asano M, Ueno Y. Endovascular stent-graft repair for abdominal aortic aneurysm in a patient with cardiac and renal dysfunction. Gen Thorac Cardiovasc Surg 2009; 57: 203-207. [CrossRef]

7. Davy Cheng, Janet Martin, Hani Shennib, Joel Dunning, Claudio Muneretto Stephan Schueler, Ludwig Von Segesser, Paul Sergeant Marko Turina. Meta-Analysis of Comparative Studies. J Am Coll Cardiol 2010; 55: 986-1001. [CrossRef] 